\title{
Narcissistic Leaders: A Review of Astonishing Success and Remarkable Failure
}

\author{
Amr Swid \\ St. Edwards University \\ Dina Ragab \\ New York Institute of Technology
}

\begin{abstract}
Narcissistic leaders are often seen as charismatic and confident leaders at first. However, self-interest and exploitation characteristics surface later and can have a destructive effect on organizations. Having narcissistic leaders within an organization can be helpful in times of crisis and major transitions because of their confidence in their ability. On the other hand, Narcissist leader's behavior has a negative effect on employee's job satisfaction, while also exhausting company resources for short-term gain. Organization's policies should regulate narcissistic behavior to use their best abilities. Women narcissist leaders are considered a less risky leader and more likely to follow organization regulations and implement them.
\end{abstract}

\section{INTRODUCTION}

This research reviews the effects of Narcissistic leadership in organizations and suggesting how leaders with this trait can have both negative and positive effects on their co-workers and the organization. While Narcissistic leadership has always had a bad reputation, however many of today's largest companies have CEO's and leaders who can be characterized as narcissistic leaders. The current research will investigate the undesired characteristics of narcissistic leaders, while also pointing the importance of some the narcissistic features to run a successful organization.

Although the word narcissistic has been long associated with characteristics like dominant, inflated self-love and self-worth, has a sense of entitlement, seek attention and only work in their best interest. However, narcissist leaders have always played a role in inspiring and taking steps in social reform, e.g., Napoleon Bonaparte (Maccoby, 2004). Just like Bonaparte, former superstar CEO's shaped the business and industrial world as we know it today, for example, Henry Ford, John D. Rockefeller, Walter Disney, or Steve Jobs. These are CEO's who had a vision, confidence, exploited technology and even reshaped the American industry. They also played a role in social reform just like past leaders who had narcissistic leadership style and vision. In other words, historically narcissistic leaders have had remarkable success in the business world however it is also essential for us to understand the distinct types of narcissism, the effect of narcissistic leadership on the organization, and lastly the difference between narcissistic male and female leaders. In sum, this research is aiming to inform organizations of the benefit-risk ratio of male and female narcissist leaders in various working context. 


\section{LITERATURE REVIEW}

\section{The Different Types of Narcissism}

One of the first researchers to analyze the different styles of narcissism was Wink (1991) who discussed the difference between "overt" and "covert" narcissistic leadership styles. Wink argued that the existing measures of narcissistic behaviors and personalities like the Narcissistic Personality Inventory (NPA; Raskin \& Hall, 1979, 1981) or the Serkownek (1975) scales only look into one or the other narcissistic personality type.

According to Wink (1991), a person who has characterized, as a covert narcissist is introvert, vulnerable and even hypersensitive (Sturman, 2000). Covert narcissistic leaders often share character elements like entitlement or explosiveness; these characteristics are often associated with aggression (Emmons, 1984). In addition to anxiety and sometimes depression as well (Watson \& Biderman, 1993), which is a result of vulnerability and hypersensitivity (Sturman, 2000). However, Sturman also discussed how both entitlement and explosiveness factors are core qualities in both covert and overt narcissistic styles. Some researchers have distinguished that overt narcissists can both see themselves and be perceived as controlling, assertive and high risk-taking as well (Raskin \& Novacek, 1989), Wink and Gough, 1990). More importantly, overt narcissism is strongly associated with self-serving dominance and desire for success and achievement (Sturman, 2000).

Unlike overt narcissists, covert narcissists have different motives and desires behind their behavior. Covert narcissists suffer from social anxiety (Watson \& Bidermann, 1993; Wink, 1991) which are a result of vulnerability as mention before. Despite this social anxiety, covert narcissists still have an unconscious desire for power, influence, and control (Sturman, 2000). While these motives and desires exist for both overt and covert narcissists, overt narcissists often pursue them more directly and openly than covert narcissists. When trying to spot the behavior of covert vs. overt narcissistic leaders, one will often find that both narcissistic leadership styles seek power and dominance while using different methods. Overt narcissism is coupled with an unrealistic interpersonal sense of superiority, but a covert narcissist practices a more defensive and self-protectiveness (Sturman, 2000).

\section{Narcissistic Leadership Inside the Organization}

Many organization leaders share common characteristics that are narcissistic. Interestingly, some of these features of narcissism are considered normal or common and may be required to run a business successfully. Therefore, it is important before moving forward with the implications to discuss the behavior and motive of narcissistic leaders in the workplace and understand their traits.

In general, narcissistic leaders have character attributes and confidence in their ability that often help them emerge into leadership positions. While narcissism may be the reason for their success, it is also often the reason behind their downfall as well because it does not guarantee leadership effectiveness as well (Cann \& Siegfried, 1990; Kark, Waismel-Manor, \& Shamir, 2012). Negative attributes which lead to low leadership effectiveness scores include the use of available resources to best serve themselves rather than the company they work for (Ouimet, 2010).

Mostly, narcissistic leaders try to show their dominance and attract admiration to verify their sense of grandiosity (Higgs, 2009; Maccoby, 2007). Interactions with a narcissistic leader can be uncomfortable and difficult on various levels and settings. However, Betan et al. (2005) points out that while there may be some benefits of narcissistic leadership style overall, interactions the beginning of any relationship usually includes many discomforts. When dealing with a narcissistic leader, there are some key factors which need to be understood and realized by others. As mentioned before, narcissistic leaders need to be constantly admired and praised by their co-workers and peers. As a result, they choose their followers and inner circle strictly to fulfill this need.

In addition to only being surrounded by those who admire them and only working for their selfinterest, narcissistic leaders are often very sensitive to any negative feedback, which brings out their aggressive reaction and feedback (Barry et al., 2006). Many times, individuals with narcissistic personality react similarly just when "perceiving a threat to the integrity of the self" (Bond et al., 2006). 
A final trait of narcissistic leaders is manipulation and the exploitation of subordinates and coworkers (Glad, 2002). It is also noticeable how narcissistic leaders have better results in the short-term versus longer periods since they work to exploit resources for temporary gain, not long-term benefits (Ong \& Roberts et al., 2016).

Past research investigated many of the features and characteristics present in many CEO's with a narcissistic personality. In an article by Ouimet (2010) the author put together a list of potential negative characteristics, which may occur in a narcissistic leader. The list included attributes like impulsive behavior (Vazire and Funder, 2006), this impulsivity can lead to acting without considering all risks as well as how such calculating how these decisions may affect the organizations' performance altogether. Similar to impulsivity, recklessness is also a trait that can be found in narcissistic leaders, which is often a result of striving towards certain results and can somehow make an organizations' results unstable and overall lacking.

\section{The Relationship between Narcissistic Leadership and Their Employees}

To highlight the destructive characteristics of narcissistic leadership that affect the leaders' environment and employees, the research will investigate this leadership style from the employee's perspective. It is undeniable that narcissistic leaders have an appealing charisma and first impression that often helps them emerge as leaders in the workplace. However, long-term relationships with narcissistic leaders can be compared to eating a chocolate cake (Ong \& Roberts, 2016; Campbell, 2005; Campbell, Hoffman, Campbell \& Marchisio, 2011).

The experience of eating a chocolate cake can be described as very gratifying when experiencing the rich texture and flavor of the cake (Ong \& Roberts, 2016). However, after the first few indulgences, the richness of the chocolate cake can have an over-satisfying and even nauseous effect (Ong \& Roberts, 2016). Just like the rich chocolate cake effect, narcissistic leaders can be perceived with admiration and respect at the beginning, but soon enough these positive attributes may fade away (Ong \& Roberts, 2016).

Employees and narcissistic leadership followers often are deceived by the leader's extroverted personality (Ong \& Roberts, 2016; Bradlee \& Emmons, 1992), social skills (Ong \& Roberts, 2016; Oltmanns et al., 2004). Also, likable appearance (Ong \& Roberts, 2016; Paulhaus, 1998), well performance in public tasks and tough situations (Ong \& Roberts, 2016). And most importantly their strong charisma (Khoo \& Burch, 2008), which makes the followers believe that this person has the necessary traits to be an effective leader.

Soon enough many of the perceived first impressions wear off and are substituted with narcissistic behavior like arrogance, overconfidence, overestimation of leaders' abilities (Ong \& Roberts, 2016), in addition to employee feeling of exploitation and negligence. In other words, newly acquainted relationships with employees may be positive. However, it may change with well-acquainted employee relationships.

\section{The Effect of Narcissistic Leadership on Employees' Satisfaction with Their Jobs}

Rantz, Stueve, \& McQuistion (2001) pointed out how many believe that job satisfaction is crucial to an organizations survival and success. While some other researchers also suggested that employees and their well-being are the keys to any organizations success. Happy employees provide organizations with a unique and "sustainable long-term competitive advantage" (Detamore, 2008; Redshaw, 2001; Coff, 1999; Ulrich, 1997; Finkelstein \& Hambrick, 1996; Judge \& Ferris, 1992; Porter, 1985 ). However, recent statistics show that employee satisfaction levels have dropped, which increased the demand for motivational leaders in organizations (Detamore, 2008; Bryman, 1992).

More importantly, to understand organizations' performance and culture, one needs to look into the relationship between leadership and employees. Additionally, employee dissatisfaction costs organizations many losses in forms of resources as well as operating costs. These operating costs include less employee productivity, pension costs, new hire recruitment, and training... etc. (Detamore, 2008; Cascio, 1991). Narcissistic leaders may have a strong effect on employees' satisfaction and role within an organization. Just like transformational leaders, narcissistic leaders usually enforce major changes in the 
organization and actively interacts with a wide range of employees to reinforce this change (Detamore, 2008). While this change may be necessary for some organizations who are looking to reform, however, many organizations are not looking to change their existing culture and structure.

A narcissistic leader will use some tactics to achieve their personal goals and get results from employees; these tactics include delay, slander, and coercion (Shurden, 2014; Grier, 2008). These actions by narcissistic leaders are often a result of a feeling of threat by some employees, who they may attempt to undercut (Lubit, 2002). Many times, the most capable employees are the ones feared most by narcissistic leaders and are underappreciated. As a result, they usually are not able to adapt to this environment, are dissatisfied with their jobs and leave the organization (Lubit, 2002).

Another type of narcissistic leaders, "arrogant, narcissistic" leadership are characterized as leaders who are willing to spend an unlimited amount of energy and time working to achieve their goals (Shurden, 2014; Godkin \& Allcorn, 2011 ). For example, if an "arrogant, narcissistic" leader is working overtime and staying late at work, he automatically expects his team and followers to do the same. Such expectations and work ethics results in an imbalance between work and social life for employees and would result in employee dissatisfaction as well (Shurden, 2014).

\section{The Difference between Male and Female Narcissistic Leaders}

Another interesting topic regarding narcissistic leadership is the difference between male and female narcissistic characteristics and styles. In this section, we will discuss the likelihood of women in CEO and executive positions to have similar narcissistic behavior and influence as men.

Thanks to social media, today CEO's and leaders aim to be transparent and ethical to prevent any scandals or bad reputation for their organizations. Organizations today strive for accountable, risk-free and transparent leaders who will have a positive input on the organization. When investigating the narcissistic behavior of CEO's, researchers tend to focus on male CEO's and address these characteristics regarding only men. The simple logical reasoning behind this phenomenon is that most CEO's are men (Zarya, 2016).

However, it is important also to understand the behavior of women CEO and their behavior as narcissistic leaders to understand if their management and leadership style is as risky and destructive as male narcissistic CEO's (Chatterjee and Hambrick, 2011). Many organizations cannot afford the risky and unethical behavior associated with narcissistic male leaders and consider female candidates instead.

When dealing with narcissist personality traits, women who demonstrate narcissistic behavior are often viewed differently than male figures (Grijavala et al., 2015). Moreover, female CEOs and leaders one must consider the different circumstances and situations that surround a woman in power and its effect on her leadership style (Jorstand, 1996).

For instance, De Hoogh et al. (2005) research concluded that female leaders, who have narcissistic leadership style, are seen as low performer leaders than narcissistic male leaders. Research results by Glass et al. (2016), Glass, and Cook (2016) indicated that organizations led by female CEO are, in general, follow and implement procedures \& policies, fairness and transparency more often compared to the male-led organizations.

A more in-depth analysis of women narcissistic leadership by Ingersoll et al. (2017) illustrated that female CEOs had scored much lower on the narcissism scale compared to male CEO participants. Similar results were demonstrated for questionable/unethical behavior and risk-taking measures, where women CEO participants scored significantly lower than male CEO participants (Ingersoll et al., 2017). Women CEO compared to narcissistic men in power tend to have a "greater ethical inclination" (Ingersoll et al., 2017; Albaum and Peterson, 2006; Betz et al. 1989). Moreover, they carry out regulations better than men (Ingersoll et al., 2017; Baldry 1987), in addition to showing more commitment to fairness, equity, and transparency (Ingersoll et al., 2017; Glass et al. 2016). 


\section{DISCUSSION}

Narcissistic leaders often focus on certain results, which can lead them to take high-risk decisions just to reach one goal. However, as per previous research' findings, this also leads a narcissistic person to take risks in anticipation of desirable performance and expectations beyond the actual and realistic performance outcomes (Campbell et al., $2004 \mathrm{a}, \mathrm{b}$ ).

The characteristics mentioned above often deal with the narcissistic leaders' decisions and effect on the organization as a whole. However, the following characteristics also affect the social environment and employees surrounding the narcissist. One of these traits is "insensitivity to social constraints" (Collins and Stukas, 2008), which most times leads to undermining the severity of inappropriate behavior in the workplace and helping employees feel comfortable and adjustment in the work environment.

Other traits include unforgiving (Eaton et al., 2006, Strelan, 2007) and need to avenge (Brown, 2004), which result in power gap and distance between all employees and managers as well as creates a hostile and unfriendly work environment. Finally, yet importantly, the trait of their failure to comprehend from their own previous mistakes (Campbell et al., $2004 \mathrm{a}, \mathrm{b}$ ), which is one of the least desirable traits in any of the executive positions. Even organizations, which enjoy the culture of seeing mistakes as learning opportunities.

Different leadership styles have different consequences for the organization they work at and represent. Organizations' senior management need to very selective and careful when choosing their leaders and making sure that they a mirror of the organizations' culture and values. For this reason, it is crucial for recruiters to identify the prospective employees' personality and leadership traits under different circumstances and situation. Recruiters should also assess the cultural factors concerning the prospective manager. A study by Foster et al. (2003) concluded that cultures with higher individualism also have more upper narcissistic members in their society.

Lastly, some organizational structure and its reward system can help control the "dark side" of narcissistic leader and keep them in check. Some ideas to help organizations prevent having a toxic work environment are:

- Implementing a rewards system based on group performance rather than individual performance.

- Designated committee to continually monitor managers, especially those of narcissistic tendency, professional performance quality

While for many organizations, a narcissistic leader is never a good fit for their values and culture except in periods of where there are economic, political or technological instability and threat. Matching with Rosenthal and Pittinsky (2006), we conclude that a confident narcissistic leader may be beneficial during these periods.

In times of instability, organizations and employees look for individuals who are confident in their ability and use their superiority to reassure other members of the organization. According to Post (2004), severe instability periods like wars, depressions, or national crisis, the nature of narcissistic leader is essential to building unity and reassures others of their ability to overcome the crisis.

Organizations will often have to deal with narcissistic leader even when trying their best to avoid them. As previously discussed, the narcissistic leader usually has the strong charisma that makes him or her likable. For that reason, it is crucial to understand the habits and motivation of narcissistic leaders, to be able to set rules and management implementations for those leaders. It is even more important to know how narcissistic leaders, affect the organization, its employees, and their job satisfaction. The narcissistic leader not only exhibits a significant effect on job satisfaction but also influencing work- social life balance and employee identity. 


\section{FUTURE RESEARCH}

The subject area of narcissistic leadership and its implication on the organizational psychology level has been thoroughly researched. However, future research may focus on the impacts and consequences of this personality trait on both managerial and employee levels. While there might be some research on narcissistic leadership on the executive level, it seems like there little to no research based on middle management. Another exciting research question would be how similar or different the impact of a narcissistic leader in different industries? We believe that it would be interesting to create measurement to be able to capture the effects of narcissism in various sectors. Lastly, another area is an in-depth analysis of the effects of cultural origin and cultural intelligence on forming narcissistic individuals and leaders.

\section{CONCLUSION}

This research explored the characteristics of a narcissistic leader and highlighted the motivation behind their actions and behavior. Narcissistic leaders are always trying to be the center of admiration which leaders them to taking high risk and explosive decisions to fulfill their needs. Other characteristics of extreme cases of narcissism in leadership are over-confidence, self-serving dominance (Sturman, 2000), controlling, and high sensitivity.

In this research, the different types of narcissism were also explained, where covert narcissism deals with individuals who are introvert, vulnerable and hypersensitive (Sturman, 2000). Overt narcissist, on the other hand, is more extraversion individuals with strong charisma, desire for control and dominance and high-risk takers as well. Both overt and covert narcissistic leadership styles can affect the performance of an organization.

Narcissistic leaders are ideal for times of crises and major transformation because they appear confident in their abilities and lead their employees who are in doubt. Otherwise, the narcissistic leader can have a negative effect on an organization and exploit its resources for their own benefits regardless of the organization's needs. A narcissistic leader can often be dangerous when an organization is trying to stabilize and secure its culture and performance. A narcissistic behavior may not be the ideal management style for those situations. Also, organizations looking to receiving awards for their management style and welcoming work environment, often steer away from narcissist leaders to avoid any risks. However, we have often mentioned that there are times and business cycles when a narcissistic leader work ethics and management style are beneficial and would help push an organization to achieve better results.

It is also essential for employees how to interact and deal with a narcissist leader. Understanding the narcissist leader and employee relationship is vital to help employees understand the importance of keeping the relationship strictly professional to avoid any exploitation. Lastly, we concluded that women CEOs, who have narcissist personality, are more likely to stabilize an organization, follow regulations, and implement them unlike high-risk taking male narcissists.

\section{REFERENCES}

Albaum, G., \& Peterson, R. A. (2006). Ethical attitudes of future business leaders. Business and Society, 45(3), 300-321.

Baldry, J. C. (1987). Income tax evasion and the tax schedule: Some experimental results. Public Finance, 42(3), 357-383.

Barry, C.T., Chaplin, W.F., \& Grafeman, S.J. (2006). Aggression following performance Feedback: the influences of narcissism, feedback valence, and comparative standard. Personality and Individual Differences, 41, 177-87.

Betan, E., Heim, A.K., Conklin, C.Z., \& Westen, D. (2005). Countertransference phenomena and personality pathology in clinical practice: an empirical investigation. American Journal of Psychiatry, 162, 890-8. 
Betz, M., O'Connell, L., \& Shepard, J. M. (1989). Gender differences in proclivity for unethical behavior. Journal of Business Ethics, 8(5), 321-324.

Bond, A.J., Ruaro, L., \& Wingrove, J. (2006), "Reducing anger induced by ego threat: use of vulnerability expression and influence of trait characteristics. Personality and Individual Differences, 40, 1087-97.

Bradlee, P. M., \& Emmons, R. A. (1992). Locating narcissism within the interpersonal circumplex and the five-factor model. Personality and Individual Differences, 13, 821-830.

Brown, R.P. (2004). Vengeance is mine: narcissism, vengeance, and the tendency to forgive. Journal of Research in Personality, 38, 576-84.

Bryman, A. (1992). Charisma and leadership in organizations. London: Sage.

Campbell, W. K., Hoffman, B. J., Campbell, S. M., \& Marchisio, G. (2011). Narcissism in organizational contexts. Human Resource Management Review, 21, 268-284.

Campbell, W.K., Bonacci, A.M., Shelton, J., Exline, J.J., \& Bushman, B.J. (2004b). Psychological entitlement: interpersonal consequences and validation of a self-report Measure. Journal of Personality Assessment, 83, 29-45.

Campbell, W.K., Goodie, A.S., \& Foster, J.D. (2004a). Narcissism, confidence, and risk Attitude. Journal of Behavioral Decision Making, 17, 297-311.

Cann, A., \& Siegfried, W. D. (1990). Gender stereotypes and dimensions of effective leader behavior. Sex Roles, 23, 413-419. http://dx.doi.org/10.1007/BF00289229

Cascio, W. F. (1991). Costing human resources: the financial impact of behavior in organizations (3rd Ed.). Boston: PWS-Kent.

Chatterjee, A., \& Hambrick, D. C. (2011). Executive personality, capability cues, and risk taking: How narcissistic CEOs react to their successes and stumbles. Administrative Science Quarterly, 56(2), 202-237.

Coff, R. W. (1999). How control in human asset-intensive firms differs from physical asset-intensive firms: A multi-level approach. Journal of Managerial Issues, 11(4), 389-405.

Collins, D.R., \& Stukas, A.A. (2008). Narcissism and self-presentation: the moderating effects of accountability and contingencies of self-worth. Journal of Research in Personality, 42, 1629-34.

De Hoogh, A. H. B., Den Hartog, D. N., \& Nevicka, B. (2015). Gender differences in the perceived effectiveness of narcissistic leaders. Applied Psychology, 64(3), 473-498.

Detamore, J.A., (2008). An analysis of relationships between job satisfaction, leadership, and intent to leave within an engineering consulting firm. Capella University, Ann Arbor, 2008.

Eaton, J., Struthers, C.W., \& Santelli, A.G. (2006). Dispositional and state forgiveness: the role of selfesteem, need for structure, and narcissism. Personality and Individual Differences, 41, 371-80.

Emmons, R.A. (1984). Factor analysis and construct validation of the narcissistic personality inventory. Journal of Personality Assessment, 48, 291-300

Finkelstein, S., \& Hambrick, D. (1996). Strategic leadership. Saint Paul, MN: West Educational Publishing.

Foster, J.D., Campbell, W.K., \& Twenge, J.M. (2003). Individual differences in narcissism: inflated selfviews across the lifespan and around the world. Journal of Research in Personality, 37, 469-86.

Glad, B. (2002). Why tyrants go too far: malignant narcissism and absolute power. Political Psychology, $23,1-37$.

Glass, C., \& Cook, A. (2016). Leading at the top: Understanding women's challenges above the glass ceiling. The Leadership Quarterly, 27(1), 51-63.

Glass, C., Cook, A., \& Ingersoll, A. (2016). Do women leaders promote sustainability? Analyzing the effect of corporate governance composition on environmental performance. Business Strategy and the Environment, 25, 495-511.

Godkin, L., \& Allcorn, S. (2011). Organizational resistance to destructive narcissistic behavior. Journal of Business Ethics, 104, 559-570. DOI 10.1007/s10551-011- 0930-x.

Grier, S. (2008). Narcissism in the workplace. (no publisher listed). 
Grijalva, E., Newman, D. A., Tay, L., Donnellan, M. B., \& Robins, R. W. (2015). Gender differences in narcissism: A meta-analytic review. Psychological Bulletin, 141(2), 261-310.

Higgs, M. (2009). The good, the bad and the ugly: leadership and narcissism. Journal of Change Management, 9, 165-78.

Ingersoll, A.R., Glass, C., Cook, A., \& Olsen, K.J. (2017). Power, Status, and Expectations: How Narcissism Manifests Among Women CEOs. Journal of Business Ethics. https://dol.org/10.1007/s10551-017-3730-0

Jose, J. (2013). Leadership for Behavioral Sciences.

Jørstad, J. (1996). Narcissism and leadership: Some differences in male and female leaders. Leadership \& Organization Development Journal, 17(6), 17-23.

Judge, T. A., \& Ferris, G. R. (1992). The elusive criterion of fit in human resources staffing decision. Human Resource Planning, 15(4), 47-68.

Kark, R., Waismel-Manor, R., \& Shamir, B. (2012). Does valuing androgyny and femininity lead to a female advantage? The relationship between gender-role, transformational leadership, and identification. The Leadership Quarterly, 23, 620-640. http://dx.doi.org/10.1016/j.leaqua .2011 .12 .012

Khoo, H. S., \& Burch, G. S. J. (2008). The "dark" side of leadership personality and transformational leadership: An exploratory study. Personality and Individual Differences, 44, 86-97.

Lubit, R. (2002). The long-term organizational impact of destructively narcissistic managers. Academy of Management Executive, 16, 127-138

Maccoby, M. (2004). Narcissistic Leaders: The Incredible Pros, the Inevitable Cons. Harvard Business Review, hbr.org/2004/01/narcissistic-leaders-the-incredible-pros-the-inevitable-cons

Maccoby, M. (2007). Narcissistic Leaders: Who Succeeds and Who Fails, Harvard Business School Press, Boston, MA.

Oltmanns, T. F., Friedman, J. N., Fiedler, E. R., \& Turkheimer, E. (2004). Perceptions of people with personality disorders based on thin slices of behavior. Journal of Research in Personality, 38, 216-229.

Ong, C.W., Roberts, R., Arthur, C.A, Woodman, T., \& Akehurst, S. (2016). The leadership is sinking A Temporal Investigation of Narcissistic Leadership. Journal of Personality, 84(2). DOI: 10.1111 jopy. 12155

Ouimet, G. (2010). Dynamics of narcissistic leadership in organizations, towards an integrated research model. Journal of Managerial Psychology, 25, 713-726.

Paulhus, D. L. (1998). Interpersonal and intrapsychic adaptiveness of trait self-enhancement: A mixed blessing? Journal of Personality and Social Psychology, 74, 1197-1208.

Porter, M. E. (1985). Competitive advantage: Creating and sustaining superior performance. New York: The Free Press.

Post, J.M. (2004). "The impact of crisis-induced stress on policymakers, ” in Post, J.M. (Ed.). Leaders and Their Followers in a Dangerous World: The Psychology of Political Behavior, Cornell University Press, Ithaca, NY, 100-22.

Rantz, J., Stueve, A., \& McQuistion, H. L. (2001). The role of the psychiatrist: Job satisfaction of medical director and staff psychiatrists. Community Mental Health Journal, 37(6), 525-539.

Raskin, R. N. \& Hall, C.S. (1979). A narcissistic personality inventory. Psychological Reports, 45, 590.

Raskin, R. N. \& Hall, C.S. (1981). The Narcissistic Personality Inventory: Alternate form reliability and further evidence of construct validity. Journal of Personality Assessment, 45, 159-162.

Raskin, R.N. \& Novacek, J. (1989). An MMPI description of the narcissistic personality. Journal of Personality assessment, 53, 66-80.

Redshaw, B. (2001). Evaluating organizational effectiveness: Measuring Business Excellence, 5(1), 1621.

Rosenthal, S.A., \& Pittinsky, T.L. (2006). Narcissistic leadership. The Leadership Quarterly, 17, 617-33.

Serkownek, K. (1975). Subscales for scale 5 and 0 of the MMPA. Unpublished manuscript. 
Shurden, S. B. (2014). Identifying the Effects of Narcissistic Leadership on Employee Job Satisfaction: A Study within the Accounting Profession. Clemson University, Ann Arbor.

Strelan, P. (2007). Who forgives others, themselves, and situations? The roles of narcissism, guilt, selfesteem, and agreeableness. Personality and Individual Differences, 42, 259-69.

Sturman, T.S. (2000). The Motivational Foundations and behavioral expressions of three narcissistic styles. Social Behavior and Personality, 28, 393-408.

Ulrich, D. (1997). Human resource champions. Boston: Harvard Business School Press.

Vazire, S., \& Funder, D.C. (2006). Impulsivity and the self-defeating behavior of narcissists. Personality and Social Psychology Review, 10, 154-65.

Watson, P.J. \& Biderman, M.D. (1993). Narcissistic Personality Inventory factors, splitting, and selfconsciousness. Journal of Personality Assessment, 61, 41-57.

Wink, P., \& Gough, H.G. (1990). New narcissism scales for the California Psychological Inventory and the MMPI. Journal of Personality Assessment, 54, 446-462.

Wink, P. (1991). Two faces of narcissism. Journal of Personality and Social Psychology, 61, 590-597.

Zarya, V. (2016). The percentage of female CEOs in the Fortune 500 drops to 4\%. Fortune. Available at: http://fortune.com/2016/06/06/women-ceos-fortune-500-2016/ 